\title{
Understanding hemostasis and thrombosis : The lesson learnt from natural models
}

\author{
Pier Mannuccio MANNUCCI, MD*
}

\begin{abstract}
Under physiologic conditions, a hemostatic balance is achieved through the effects of natural procoagulant and anticoagulant factors which, in equilibrium with each other, provide hemostasis at the sites of vascular injury. Abnormalities of these hemostasis factors result in a tendency towards hemorrhagic or thrombotic events. In this review the influence of inherited prothrombotic risk factors - especially the frequent factor $\mathrm{V}$ Leiden and prothrombin gene mutations - on normal and abnormal hemostasis is analyzed from an evolutionary point of view. The effect of inherited bleeding disorders on the development of thrombotic or atherosclerotic processes is also discussed.
\end{abstract}

Key words: thrombophilia, bleeding disorders, venous thromboembolism, atherothrombosis

\section{Introduction}

The hemostatic balance is the result of a delicate equilibrium between procoagulant and anticoagulant factors that interact with each other to ensure effective hemostasis at the sites of vascular injury. However, structural abnormalities and/or changes in the levels of the different components of the hemostatic system can result in disturbances that may cause bleeding or thrombotic disorders. Mechanisms of hemorrhage include defects of coagulation factors (the hemophilias) and platelet function (Glanzmann thrombasthenia, Bernard-Soulier syndrome and von Willebrand disease), while mechanisms of thrombosis include the deficiency of naturally occurring anticoagulants (antithrombin, protein $\mathrm{C}$ and protein $\mathrm{S}$ ), increased plasma levels of coagulation factors (fibrinogen, factor VIII, von Willebrand factor) and gain-of-function of coagulation factors (factor V Leiden, and prothrombin gene mutations $)^{1)-3 \text { ) }}$. Among the inherited prothrombotic risk factors, the factor $\mathrm{V}$ Leiden mutation, which causes resistance to activated protein C (APC) due to the substitution of adenine to guanine at nucleotide 1691 at the cleavage site (Arg506) of activated factor $\mathrm{V}$ by $\mathrm{ACP}$, is present in heterozygosity in about 5 percent of Caucasians, but is absent in Africans, Chinese, Japanese and native North and South Americans ${ }^{4)}$. Haplotype analyses suggest a single origin for the mutation, which is estimated to have arisen approximately 22,000 years ago well after the evolutionary separation of nonAfricans from Africans (which occurred approximately 100,000 years ago) and of

\footnotetext{
* The Angelo Bianchi Bonomi Hemophilia and Thrombosis Center, Department of Medicine and Medical Specialities, University of Milan and IRCCS Maggiore Hospital, Mangiagalli and Regina Elena Foundation, Milan, Italy〔Via Pace 9, 20122 Milan-Italy]

Tel: +39-02-55035421 Fax: +39-02-50320723 e-mail: piermannucio.mannucci@unimi.it
} 
Caucasoid from Mongoloid populations (which occurred approximately 40,000 years ago $)^{5)}$. At more or less the same time of mankind evolution a single genetic origin occurred for another common gain-of-function mutation, the G20210A mutation in the prothrombin gene. Among Caucasians, the prevalence of factor II G20210A heterozygotes is 1 to 6 percent, whereas in nonCaucasian populations the mutation is very rare or absent, as for factor V Leiden ${ }^{6)}$. Both mutations are associated with an increased risk of venous thromboembolism ${ }^{7) 8}$, and a metaanalysis indicates that they also confer a mildly increased risk of arterial thromboembolic disease ${ }^{9)}$. However, due to their prevalence and persistence through millennia among Caucasians, it is unlikely that these mutations have only deleterious effects on health, because evolutionary selection pressure would have already led to their elimination from the human genome $^{10)}$. Why are thrombophilic mutations so frequent? Do they really give "bad blood"10) or do they afford evolutionary advantages, as sickle cell anemia, thalassemia and glucose-6-phosphate dehydrogenase deficiency do in terms of protection from malaria? And, on the other side of the hemostatic balance, does the hypocoagulability underlying inherited bleeding disorders confer protection against thrombosis and/or atherosclerosis?

\section{The hemostatic balance : thrombosis}

There is increasing evidence that gain-offunction prothrombotic mutations modulate the hemostatic balance by decreasing the amount of bleeding in a number of physiological and clinical situations. In a retrospective study, Lindqvist et al. compared the peri-partum blood loss in women with or without factor V Leiden ${ }^{11)}$.
Significantly lower blood losses $(318 \mathrm{ml}$ vs. 380 $\mathrm{ml}, \mathrm{P}=0.018$ ) and a smaller difference between pre- and post-partum hemoglobin $(0.30 \mathrm{~g} / \mathrm{dl}$ vs. $0.80 \mathrm{~g} / \mathrm{dl}, \mathrm{P}=0.02$ ) were found in carriers of the mutation. Subsequently, the same authors demonstrated that carriership of factor V Leiden was associated with higher hemoglobin and serum ferritin and reduced menstrual blood loss ${ }^{12)}$, suggesting that the gain-of-function mutation might have conferred to women an evolutionary advantage by protecting them against bleeding at parturition and menses.

Another possible pregnancy-related evolutionary benefit was surmised by Gopel et al. ${ }^{13)}$, who investigated 102 mother-child pairs who successfully underwent $i n$-vitro fertilization and found that the first embryo implantation was successful in 90 percent of mother-child pairs carrying the factor V Leiden, compared with 49 percent $(\mathrm{P}=0.018)$ in factor $\mathrm{V}$ Leiden negative pairs. Furthermore, the median number of unsuccessful transfers of embryos was smaller in pairs positive for the mutation than in those who were negative $(\mathrm{P}=0.02)$ suggesting that improved implantation rate is an important advantage provided by hypercoagulability associated with the factor V Leiden mutation.

Other studies have analyzed the influence of gain-of-function mutations of coagulation factors on hemorrhage in conditions other than parturition. Corral et al. ${ }^{14)}$ conducted a study on 201 patients with spontaneous intracranial hemorrhage and a corresponding number of controls and found that the presence of factor $\mathrm{V}$ Leiden reduced the risk of intracranial hemorrhage by 5 -fold ( $1 \%$ vs. $4.9 \%, \mathrm{P}=0.019$ ). In addition, the frequency of the G20210A prothrombin mutation in patients was half that in controls, while carriers of the -323 insertion in the factor VII gene promoter, associated with 
lower factor VII levels and hence with a mild hypocoagulability, had a 1.5 -fold increased risk of intracranial hemorrhage. A more recent study, carried out in 103 adults with subarachnoid hemorrhage ${ }^{15)}$ suggested that the platelet glycoprotein IIIa polymorphism HPA-1 (PlA), which causes platelet hyper-reactivity, has a protective role. By contrast, Navarro-Nunez et al. ${ }^{16)}$ observed that the $\beta 1$-tubulin platelet polymorphism $\mathrm{Q} 43 \mathrm{P}$, by causing a lower reactivity of platelets, protects against thrombotic disorders but increases the risk of intracerebral hemorrhage. Gopel et al. ${ }^{17)}$ analyzed 305 preterm, very low birth weight infants and found a low prevalence of intraventricular hemorrhage in those carrying the factor $\mathrm{V}$ Leiden or prothrombin G20210A mutation (OR 0.11, CI 0.02-0.5), suggesting that a heightened coagulability due to gain-of-function mutations helps to prevent the occurrence of intraventricular bleeding in very low birth weight infants. However, other studies on the influence of these mutations in very low birth weight infants produced conflicting results ${ }^{18) 19)}$. An additional piece of evidence that these mutations decrease bleeding stems from a study conducted on 517 patients undergoing cardiac surgery, including 26 heterozygous factor $\mathrm{V}$ Leiden carriers ${ }^{20}$. Donahue et al. ${ }^{20)}$ demonstrated that the gain-of-function mutation protects from blood loss and reduces transfusion requirements after cardiac surgery, the epitome of surgical operations associated with major blood loss.

Primitive men were hunters but were also preys of animals and of their peers. Bleeding and infections were conditions that primitive men had to tackle as consequences of the wounds suffered in their "fight and flight". Several studies have evaluated whether or not gain-of-function mutations offered protection from infections. The effect of the factor $\mathrm{V}$ Leiden mutation on survival in sepsis was first studied by Kerlin et al. in an endotoxin mouse model and in a large human clinical trial, the PROWESS study (recombinant human activated Protein C Worldwide Evaluation in Severe Sepsis ${ }^{21)}$. There was a lower mortality in heterozygous factor V Leiden mice and a lower 28-day mortality in patients with heterozygous factor V Leiden than in those without (13.9\% vs. $27.9 \%, \mathrm{P}=0.013$ ), suggesting that the beneficial effect of the gain-of-function mutation might be related to the increase of the anticoagulant effect of protein $\mathrm{C}$ activation by enhanced thrombin formation. However, the protective effect of factor $\mathrm{V}$ Leiden on sepsis was not confirmed in two subsequent studies. Yan and Nelson ${ }^{22)}$ combined the results of PROWESS and ENHANCE (Extended Evaluation of Recombinant Human APC) recruiting 3894 adults with severe sepsis and found no statistically significant difference in the 28-day mortality between heterozygous factor V Leiden carriers and non-carriers (20.3\% vs. $24.9 \%$; risk ratio 0.82 , CI $0.57-1.17$ ). In a population-based study (the Copenhagen City Heart Study involving 1093 patients hospitalized for infections), Nelson et al. ${ }^{23)}$ found that the 28-day mortality for sepsis was actually increased in carriers of factor V Leiden.

\section{The hemostatic balance : bleeding}

In order to provide further support to the evolutionary model of the hemostatic balance, some authors have evaluated whether or not gain-of-function mutations provide selective advantages in patients with inherited bleeding disorders by modulating the clinical phenotype ${ }^{24)}$. It is well known that there is a great variability in the pattern and age of onset of bleeding among patients with severe hemophilia and that a subset 
of patients who have severe hemophilia on laboratory testing (factor level less than 1\% of normal) has a mild clinical phenotype ${ }^{25)}$.

Why do these differences occur and what is their explanation? Besides the possibility that the type of mutation within the factor VIII gene may influence the clinical severity of hemophilia ${ }^{26) 27)}$ it has recently been suggested that prothrombotic gene mutations modulate clinical phenotype ${ }^{28)}$. In 1996, Nichols et al. ${ }^{29)}$ studied the factor V Leiden mutation in two sets of hemophiliacs who had identical factor VIII gene mutations but different disease severity and suggested that co- $^{-}$ inheritance of factor V Leiden conferred a clinical benefit. Ghosh et al. ${ }^{30)}$ described 11 patients with a milder clinical presentation of hemophilia $\mathrm{A}$ and found that 8 of them had one or more inherited prothrombotic factors (i.e., protein $\mathrm{C}$, protein $\mathrm{S}$ and antithrombin deficiencies, heterozygosity for factor V Leiden and for methylenetetrahydrofolat e reductase (MTHFR) gene polymorphism C677T). Ettinghausen et al. ${ }^{31)}$ evaluated 124 previously untreated children with hemophilia A and found that those carrying the factor $\mathrm{V}$ Leiden mutation had their first bleeding episode at a later time in life than did non-carriers. These results were confirmed by Nowak-Göttl et al. ${ }^{32)}$ and by Lee et $\mathrm{al}^{33)}$. Moreover, the latter group showed that coagulation factor usage for treatment of bleeding was lower in carriers of the Leiden mutation than in those without.

The molecular mechanism by which factor $\mathrm{V}$ Leiden affects the hemophilia phenotype seems to be related to an increase in thrombin generation by reducing thrombin down-regulation through the APC pathway. In an in vitro model, van't Veer et al. $^{34)}$. demonstrated that thrombin formation was increased in the presence of factor $\mathrm{V}$ Leiden when all the factors of the protein $\mathrm{C}$ pathway were present in the reaction. Activated factor $\mathrm{V}$ has a cofactor function in the proteolysis of factor VIII by APC. However, proteolytic degradation is considerably smaller in the presence of activated factor $\mathrm{V}$ ( FVa). The inactivation of FVa Leiden is slower than that of wild-type FVa. Thus, FVa Leiden may protect factor VIII against APC-induced inactivation.

In contrast, other groups failed to observe a decrease in bleeding in hemophiliacs carrying factor V Leiden ${ }^{35)-37)}$. Arbini et al. ${ }^{35)}$ evaluated 21 patients with severe hemophilia A or B and a milder clinical phenotype and found that only one of them was a carrier of factor $\mathrm{V}$ Leiden mutation. Similarly, Arruda et al. ${ }^{36)}$ found that 3 of 113 patients with hemophilia of different severity had co-inherited the factor V Leiden mutation but failed to detect a difference in the frequency of bleeding episodes or need for replacement therapy between patients with or without the mutation. Finally, Araujo et al. ${ }^{37)}$ screened 37 patients with hereditary disorders for various prothrombotic mutations but found no protective effect on clinical bleeding by any of the mutations. The modifying role of prothrombotic gene mutations was also evaluated in patients with inherited hemorrhagic diseases other than hemophilia. For instance, Castoldi et al. reported that the coinheritance of FV Leiden in patients homozygous for the FVII Lazio mutation was associated with a milder bleeding phenotype ${ }^{38)}$. On the whole, these data are quite contradicting and inconclusive, and fail to establish convincingly that a mild clinical expression of a severe bleeding disorder is explained by the presence of the factor $\mathrm{V}$ Leiden mutation or other prothrombotic factors.

A number of studies analyzed the opposite side of the hemostatic balance, i.e. whether or not the presence of a hemostatic defect provides protection from thrombosis. Cardiovascular events due to thrombosis are uncommon in 
hemophiliacs. In a long-term follow-up of Dutch hemophiliacs, Triemstra et al. ${ }^{39)}$ found that the risk of fatal ischemic heart disease in this population was $80 \%$ lower than expected, suggesting that severe and moderately severe hemophilia offers protection against ischemic heart disease ${ }^{39)}$. These data have been confirmed by the recent observation that a reduction of coagulation factors VIII and IX to approximately 50 percent of normal in female carriers of hemophilia A and B protected them from ischemic heart disease ${ }^{40)}$. Kiechl and Willeit ${ }^{41)}$ suggested that iron depletion associated with recurrent bleeding, could explain the decreased risk of thrombosis.

On the other hand, Salomon et al. ${ }^{42)}$ found that severe factor XI deficiency, unlike factor VIII and IX deficiency, did not confer protection against acute myocardial infarction. Ultrasonographically measured intima-media thickness in the carotid and femoral arteries of patients with inherited bleeding disorders (hemophilia and von Willebrand disease) was not different from that in healthy controls, indicating that hereditary conditions characterized by decreased coagulability have no relevant protective effect against atherosclerosis ${ }^{43}$. Further studies on patients with inherited defects of primary hemostasis have confirmed these findings using the same method. A study conducted on 7 patients with Glanzmann thrombasthenia ${ }^{44)}$ found no significant differences in intima-media thickness and atherosclerotic plaques between patients and controls. Similar results were found in a recent multicenter study conducted in 47 patients with type 3 von Willebrand disease the most severe form due to marked defects of the platelet adhesive glycoprotein von Willebrand factor $^{45)}$.

In all, these results, along with the findings of a decreased thrombotic tendency in animal models of von Willebrand disease and Bernard-Soulier syndrome ${ }^{46) 47)}$, corroborate the hypothesis that primary hemostasis (i.e., platelets and von Willebrand factor) does not play a role in the development and extent of the atherosclerotic process, and that the putative protection from atherothrombotic cardiovascular disease observed in epidemiological studies carried out in patients with hemophilia is perhaps due to protection from thrombus formation on atherosclerotic plaques ${ }^{48)}$.

\section{Learning points}

The hypothesis that evolutionary advantages have maintained gain-of-function prothrombotic mutations that developed approximately 22,000 years ago in the pre-Neolithic man is very intriguing. In the primitive man, bleeding from wounds and parturition was a frequent and prominent event in daily life. The same men were lean and physically active, so that thrombosis was not a cogent problem, also due to their relatively short lifespan. On the other hand, the modern man can become much older, is often overweight and physically inactive, so that the prothrombotic impact of the gain-of-function mutations is overtaking the protective effects on hemorrhage. The protection from thrombosis conferred by inherited disorders of hemostasis gave no evolutionary advantage to the primitive man, and affected individuals usually bled to death at birth or very early afterwards. The most likely explanation for the maintenance of hemophilia throughout the centuries is the high rate of spontaneous mutations in the corresponding genes. 


\section{References}

1) Lane D, Mannucci PM, Bauer KA, Bertina RM, Bochkov NP, Boulyjenkov V, Chandy M, Dahlback B, Ginter EK, Miletich JP, Rosendaal FR, Seligsohn U : Inherited thrombophilia : Part I. Thromb Haemost 76 : 651-662, 1996.

2) De Stefano V, Finazzi G, Mannucci PM : Inherited thrombophilia : pathogenesis, clinical syndromes, and management. Blood 87 : 3531-3544, 1996.

3) Franchini M, Veneri D, Salvagno GL, Manzato F, Lippi G : Inherited thrombophilia. Crit Rev Clin Lab Sci 43 : 249-290, 2006.

4) Rees DC, Cox M, Clegg JB : World distribution of factor V Leiden. Lancet 346 : 1133-1134, 1995.

5) Zivelin A, Griffin JH, Xu X, Pabinger I, Samama M, Conard J, Brenner B, Eldor A, Seligsohn U : A single genetic origin for a common Caucasian risk factor for venous thrombosis. Blood 89 : 397-402, 1997.

6) Zivelin A, Mor-Cohen R, Kovalsky V, Kornbrot N, Conard J, Peyvandi F, Kyrle PA, Bertina R, Peyvandi F, Emmerich J, Seligsohn U : Prothrombin 20210G $>$ A is an ancestral prothrombotic mutation that occurred in whites approximately 24,000 years ago. Blood $107: 4666-4668$, 2006.

7) Bertina RM, Koeleman BP, Koster T, Rosendaal FR, Dirven RJ, de Ronde H, van der Velden PA, Reitsma PH : Mutation in blood coagulation factor $\mathrm{V}$ associated with resistance to activated protein C. Nature 369 : 64-67, 1994.

8) Poort SR, Rosendaal FR, Reitsma PH, Bertina RM : A common genetic variation in the 3 -untranslated region of the prothrombin gene is associated with elevated plasma prothrombin levels and an increase in venous thrombosis. Blood 88 : 3698-3703, 1996.

9) Ye Z, Liu EH, Higgins JP, Keavney BD, Lowe GD, Collins $\mathrm{R}$, Danesh J : Seven haemostatic gene polymorphisms in coronary disease: meta-analysis of 66,155 cases and 91,307 controls. Lancet 367 : 651-658, 2006.

10) Majerus PW : Bad blood mutation. Nature 369 : 14-15, 1994.

11) Lindqvist PG, Svensson PJ, Dahlback B, Marsal K : Factor $V$ Q506 mutation (activated protein $\mathrm{C}$ resistance) associated with reduced intrapartum blood loss-a possible evolutionary selection mechanism. Thromb Haemost 79 : 69-73, 1998.

12) Lindqvist PG, Zoller B, Dahlback B : Improved hemoglobin status and reduced menstrual blood loss among female carriers of factor V Leiden-an evolutionary advantage? Thromb Haemost 86 : 1122-1123, 2001.

13) Gopel W, Ludwig M, Junge AK, Kohlmann T, Diedrich $\mathrm{K}$, Moller J : Selection pressure for the factor-V-Leiden mutation and embryo implantation. Lancet $358:$ 1238-1239, 2001.

14) Corral J, Iniesta JA, Gonzalez-Conejero R, Villalon M, Vicente V : Polymorphisms of clotting factors modify the risk for primary intracranial hemorrhage. Blood 97 : 2979-2982, 2001.

15) Iniesta JA, Gonzalez-Conejero R, Piqueras C, Vicente V, Corral J : Platelet GP IIIa polymorphism HPA-1 (P1A) protects against subarachnoid hemorrhage. Stroke 35 : 2282-2286, 2004.

16) Navarro-Nunez L, Lozano ML, Rivera J, Corral J, Roldan $\mathrm{V}$, Gonzalez-Conejero R, Iniesta JA, Montaner J, Vicente $\mathrm{V}$, Martinez C : The association of the $\beta 1$-tubulin QP34 polymorphism with intracerebral hemorrhage in men.
Haematologica 92 : 513-518, 2007.

17) Gopel W, Gortner L, Kohlmann T, Schultz C, Moller J : Low prevalence of large intraventricular haemorrhage in very low birthweight infants carrying the factor $\mathrm{V}$ Leiden or prothrombin G20210A mutation. Acta Paediatr 90 : 1021-1024, 2001.

18) Petaja J, Hiltunen L, Fellman V : Increased risk of intraventricular hemorrhage in preterm infants with thrombophilia. Pediatr Res 49 : 643-646, 2001.

19) Hartel C, Konig I, Koster S, Kattner E, Kuhls E, Koster H, Moller J, Moller D, Kribs A, Segerer H, Wieg C, Herting E, Gopel W : Genetic polymorphisms of hemostasis genes and primary outcome of very low birth weight infants. Pediatrics 118 : 683-689, 2006.

20) Donahue BS, Gailani D, Higgins MS, Drinkwater DC, George AL Jr : Factor V Leiden protects against blood loss and transfusion after cardiac surgery. Circulation 107 : 1003-1008, 2003.

21) Kerlin BA, Yan SB, Isermann BH, Brandt JT, Sood R, Basson BR, Joyce DE, Weiler H, Dhainaut JF : Survival advantage associated with heterozygous factor $\mathrm{V}$ Leiden mutation in patients with severe sepsis and in mouse endotoxemia. Blood 102 : 3085-3092, 2003.

22) Yan SB, Nelson DR : Effect of factor V Leiden polymorphism in severe sepsis and on treatment with recombinant human activated protein C. Crit Care Med 32 (5 Suppl) : S239-246, 2004.

23) Benfield TL, Dahl M, Nordestgaard BG, Tybjaerg-Hansen A : Influence of the factor V Leiden mutation on infectious disease susceptibility and outcome : a population-based study. J Infect Dis 192 : 1851-1857, 2005.

24) Franchini $M:$ Thrombotic complications in patients with hereditary bleeding disorders. Thromb Haemost 92 : 298-304, 2004.

25) van Dijk K, van der Bom JG, Fischer K, Grobbee DE, van den Berg HM : Do prothrombotic factors influence clinical phenotype of severe hemophilia? A review of the literature. Thromb Haemost $92:$ 305-310, 2004.

26) Oldenburg J, Schroder J, Schmitt C, Brackmann HH, Schwaab R : Small deletion/insertion mutations within poly-A runs of the factor VIII gene mitigate the severe hemophilia A phenotype. Thromb Haemost 79 : 452-453, 1998.

27) Young M, Inaba H, Hoyer LW, Higuchi M, Kazazian HH Jr, Antonarakis SE : Partial correction of a severe molecular defect in hemophilia A because of errors during expression of the factor VIII gene. Am J Hum Gen 60 : 565-573, 1997.

28) Dargaud Y, Meunier S, Negrier C : Haemophilia and thrombophilia : an unexpected association! Haemophilia $\mathbf{1 0}$ : 319-326, 2004.

29) Nichols WC, Amano K, Cacheris PM, Figueiredo MS, Michaelides K, Schwaab R, Hoyer L, Kaufman RJ, Ginsburg D : Moderation of hemophilia A phenotype by the factor V R506Q mutation. Blood 88 : 1183-1187, 1996.

30) Ghosh K, Shetty S, Mohanty D : Milder clinical presentation of haemophilia A with severe deficiency of factor VIII as measured by one-stage assay. Haemophilia 7 : 9-12, 2001.

31) Escuriola Ettingshausen $C$, Halimeh S, Kurnik K, Schobess R, Wermes C, Junker R, Kreuz W, Pollmann H, Nowak-Gottl $\mathrm{U}$ : Symptomatic onset of severe hemophilia A in childhood is dependent on the presence of prothrombotic risk factors. Thromb Haemost 85 : 218-220, 2001.

32) Nowak-Göttl U, Escuriola C, Kurnik K, Schobess R, Horneff S, Kosch A, Kreuz W, Pollmann H : Haemophilia 
and thrombophilia. What do we learn about combined inheritance of both genetic variations? Hamostaseologie 23 : 36-40, 2203.

33) Lee DH, Walker IR, Teitel J, Poon MC, Ritchie B, Akabutu J, Sinclair GD, Pai M, Wu JW, Reddy S, Carter C, Growe G, Lillicrap D, Lam M, Blajchman MA : Effect of the factor $\mathrm{V}$ Leiden mutation on the clinical expression of severe hemophilia A. Thromb Haemost 83 : 387-389, 2000.

34) van't Veer C, Golden NJ, Kalafatis M, Simioni P, Bertina $\mathrm{RM}$, Mann KG : An in vitro analysis of the combination of hemophilia A and factor V Leiden. Blood 90 : 3067-3072, 1997.

35) Arbini AA, Mannucci PM, Bauer KA : Low prevalence of the factor V Leiden mutation among "severe" hemophiliacs with a "milder" bleeding diathesis. Thromb Haemost 74 : 1255-1258, 1995.

36) Arruda VR Aannichino Bizzacchi JM, Antunes SV, Costa FF : Association of severe hemophilia A and factor V Leiden : report of three cases. Haemophilia 2 : 51-53, 1996.

37) Araújo F, Fraga M, Henriques I, Monteiro F, Meireles E, Pereira C, Lacerda P, Cunha-Ribeiro LM : The clinical phenotype modulation of haemophilia by prothrombotic gene mutations. Haemophilia $9:$ 235-236, 2003.

38) Castoldi E, Govers-Riemslag JW, Pinotti M, Bindini D, Tans G, Berrettini M, Mazzucconi MG, Bernardi F, Rosing J : Coinheritance of factor V (FV) Leiden enhances thrombin formation and is associated with a mild bleeding phenotype in patients homozygous for the FVII $9726+5 \mathrm{G}>\mathrm{A}$ (FVII Lazio) mutation. Blood 102 : 4014-4020, 2003.

39) Triemstra M, Rosendaal FR, Smit C, Van der Ploeg HM, Briet $\mathrm{E}$ : Mortality in patients with hemophilia. Changes in a Dutch population from 1986 to 1992 and 1973 to 1986 . Ann Intern Med 123 : 823-827, 1995.

40) Šrámek A, Kriek M, Rosendaal FR : Decreased mortality of ischemic heart disease among carriers of hemophilia. Lancet 362 : 351-354, 2003.
41) Kiechl S, Willeit J : Cardiovascular protection in haemophilia. Lancet 362 : 2026, 2003.

42) Salomon O, Steinberg DM, Dardik R, Rosenberg N, Zivelin A, Tamarin I, Ravid B, Berliner S, Seligsohn U. Inherited factor XI deficiency confers no protection against acute myocardial infarction. J Thromb Haemost 1 : 658-661, 2003.

43) Sramek A, Reiber JH, Gerrits WB, Rosendaal FR : Decreased coagulability has no clinically relevant effect on atherogenesis : observations in individuals with a hereditary bleeding tendency. Circulation $104: 762-767,2001$.

44) Shpilberg O, Rabi I, Schiller K, Walden R, Harats D, Tyrrell KS, Coller B, Seligsohn U : Patients with Glanzmann thrombasthenia lacking platelet glycoprotein alpha (IIb) beta (3) (GPIIb/IIIa) and alpha (v) beta (3) receptors are not protected from atherosclerosis. Circulation 105 : 1044-1048, 2002.

45) Sramek A, Bucciarelli P, Federici AB, Mannucci PM, De Rosa V, Castaman G, Morfini M, Mazzucconi MG, Rocino A, Schiavoni M, Scaraggi FA, Reiber JH, Rosendaal FR : Patients with type 3 severe von Willebrand disease are not protected against atherosclerosis : results from a multicenter study in 47 patients. Circulation 109 : 740-744, 2004.

46) Nichols TC, Bellinger DA, Johnson TA, Lamb MA, Griggs TR : von Willebrand's disease prevents occlusive thrombosis in stenosed and injured porcine coronary arteries. Circ Res $59: 15-26,1986$.

47) Strassel C, Nonne C, Eckly A, David T, Leon C, Freund M, Cazenave JP, Gachet C, Lanza F : Decreased thrombotic tendency in mouse models of the Bernard-Soulier syndrome. Arterioscler Thromb Vasc Biol 27 : 241-247, 2007.

48) Martinelli I : von Willebrand factor and factor VIII as risk factors for arterial and venous thrombosis. Semin Hematol $42:$ :4-55, 2005. 